\title{
O que acontece atrás das grades: estratégias de prevenção desenvolvidas nas delegacias civis contra HIV/AIDS e outras doenças sexualmente transmissíveis
}

\author{
What happens behind bars: prevention strategies developed \\ in civilian police stations against HIV/AIDS \\ and other sexually transmitted diseases
}

Cássia Barbosa Reis ${ }^{1}$

Erica Bento Bernardes ${ }^{2}$

\footnotetext{
${ }^{1}$ Universidade Estadual de Mato Grosso do Sul. Cidade Universitária, Rod. Dourados/Itaum, Rural Caixa-Postal 351 79804-970 Dourados MS. cassia@uems.br

${ }^{2}$ Prefeitura Municipal de Japorã.
}

\begin{abstract}
Brazilian Preventive Healthcare Policy has implemented important strategies to combat the spread of HIV/AIDS. However, there are some individuals that are theoretically not part of society who are catching and transmitting disease, namely prisoners. This population interacts with the community by means of relatives, visitors, prison wardens and repeat incarceration. The scope of this research is to establish the strategies developed to prevent the transmission and dissemination of STD/AIDS in Civil Police stations. A qualitative study was conducted with interns of the public prisons of four cities of the region of Naviraí in Mato Grosso do Sul State, and analysis was applied using the collective subject discourse technique. Results showed that despite acknowledging the importance of prevention, the male condom is only used in the first sexual encounter, and condoms are not used when intercourse is with a steady partner. The lack of orientation in relation to prevention of STD/ AIDS is well-known as is the lack of attention to the healthcare of prisoners, due mainly to prejudice and discrimination by society. It was revealed that a healthcare policy for prisoners also needs to be implemented in public prisons.
\end{abstract}

Key words Sexually Transmitted Diseases, Prevention, Incarceration Population
Resumo A Politica de Saúde Preventiva brasileira tem realizado importantes estratégias de combate a disseminação do HIV/AIDS. Porém, existem individuos que, teoricamente, não fazem parte da sociedade e são receptores e transmissores de doenças: os encarcerados. Esta população interage com a comunidade por meio dos familiares, visitantes, servidores prisionais e das diversas reincidências. Esta pesquisa teve como objetivo conhecer as estratégias desenvolvidas para prevenir a infecção e a disseminação das DST/AIDS nas Delegacias Civis. De desenho qualitativo, foi realizada com internos das cadeias públicas de quatro municípios da regional de Naviraí/MS, sendo a análise realizada através da técnica do discurso do sujeito coletivo. Resultados mostram que apesar de reconhecerem a importância da prevenção, o preservativo masculino é utilizado apenas na primeira relação, sendo que quando se trata de relacionamento com parceiro (a) fixo (a) este não é usado. É notória a falta de orientação em relação à prevenção das DST/AIDS e a precária assistência à saúde dos presos, relacionado principalmente ao preconceito e à discriminação da sociedade. Ficou evidenciada a necessidade de que a politica de atenção à saúde dos prisioneiros precisa ser implantada também nas cadeias públicas.

Palavras-chave Doenças Sexualmente Transmissíveis, Prevenção, População privada de liberdade 


\section{Introdução}

É de conhecimento da sociedade, civil e científica, que a Síndrome da Imunodeficiência Adquirida (AIDS) representa uma ameaça em potencial para a integridade da saúde sob todos os seus aspectos. Diante desse fato, estudiosos dedicam-se a desenvolver drogas a fim de contribuir com a sobrevida após a infecção pelo Vírus da Imunodeficiência Humana (HIV).

A Síndrome da Imunodeficiência Adquirida (AIDS) é mais grave e conhecida das DST. É uma doença emergente, que representa um dos maiores problemas de Saúde Pública da atualidade em virtude de seu caráter pandêmico e à gravidade ${ }^{1}$.

Contudo, não se deve negar que a política de saúde preventiva brasileira tem realizado importantes estratégias de combate à disseminação do HIV/AIDS, as quais obtiveram elogios internacionais. Podemos destacar como principais métodos a distribuição universal de medicamentos antiretrovirais, as campanhas que estimulam o uso do preservativo, o controle da qualidade dos hemoderivados dos bancos de sangue e hospitais e a considerável redução da transmissão vertical do HIV.

Dados estatísticos sobre a prevalência e a incidência da AIDS evidenciam que houve uma significativa mudança no que concerne ao indivíduo infectado. Na década de 80 , mais da metade dos indivíduos infectados eram pessoas brancas, com escolaridade superior a oito anos e atingia, em grande escala, a comunidade homossexual. Hoje, o acometimento da infecção estendeu-se aos negros, à população de baixa escolaridade e heterossexual, sobretudo à população feminina ${ }^{2}$.

Para os homens, há uma redução dos indivíduos com maior escolaridade no decorrer dos anos, porém para as mulheres, desde o início da epidemia as proporções no grupo de menor escolaridade já ultrapassam $70 \%$, se mantendo relativamente estáveis².

A ocorrência das Doenças Sexualmente Transmissíveis (DST) é também frequentemente apontada como um fator de risco adicional para a infecção pelo HIV. Uma das razões possíveis é que a presença de uma DST em um dos parceiros potencializa o risco da transmissão do HIV. Por outro lado, não se pode considerar que os fatores de risco são os mesmos e que estes assumem ainda maior relevância, em virtude dos efeitos da interação sexual seletiva das redes sociais ${ }^{3}$.

O Ministério da Saúde ${ }^{1}$ classifica como indivíduos que frequentemente apresentam compor- tamento de risco e alta vulnerabilidade para a infecção, os usuários de drogas injetáveis, profissionais do sexo, caminhoneiros, garimpeiros e, principalmente, os presidiários.

Os próprios representantes de entidades e de programas federais destinados a fornecer informações e a elaborar ações de prevenção admitem que não foi dada atenção necessária à população carcerária. Devido às condições precárias dos sistemas prisionais, não somente com relação à saúde, mas também aos processos penais demasiadamente demorados, estrutura física, alimentação, habitação e profissionalização; resta ao interno poucas opções, de forma que a AIDS, e outras doenças infecciosas de alta morbidade, sejam conclusões antecipadas de sua condenação.

A população prisional brasileira, gira em torno de duzentos e trinta mil pessoas. Mais da metade dos presos tem menos de trinta anos, $95 \%$ são pobres, $95 \%$ são do sexo masculino, dois terços não completaram o primeiro grau e cerca de $12 \%$ são analfabetos ${ }^{4}$.

A população confinada nas penitenciárias, distritos policiais e cadeias públicas quase não têm acesso aos serviços de saúde, sendo essa uma das razões de inúmeras e simultâneas manifestações de revolta, com uso da violência no interior do sistema prisional brasileiro ${ }^{5}$.

No ano de 2003, através da Portaria Interministerial n. ${ }^{\circ}$ 1.777, de nove de setembro, instituiu-se o Plano Nacional de Saúde no Sistema Penitenciário (PNSSP), que contempla a população recolhida em penitenciárias, presídios, colônias agrícolas e/ou agroindustriais e hospitais de custódia e tratamento, não incluindo presos do regime aberto e presos provisórios, recolhidos em cadeias públicas e distritos policiais ${ }^{6}$.

Os estabelecimentos mais lotados são, geralmente, as Delegacias de Polícia Civil. Ao invés de serem usadas para a detenção de suspeitos logo após sua prisão, e por curto espaço de tempo, as delegacias policiais de vários estados mantêm detentos por longos períodos, e até mesmo anos. Cinquenta e um por cento da população confinada está detida em cadeias públicas e apenas $49 \%$ cumprem pena em presídios ${ }^{4}$. Porém, dados mais recentes do Ministério da Saúde ${ }^{6}$ (p. 12) afirmam que " $75 \%$ dos presos estão recolhidos em presídios e penitenciárias, unidades destinadas a presos condenados à pena de reclusão em regime fechado".

A população prisional causa particular preocupação pela alta prevalência de HIV, hepatites B e C e outras doenças sexualmente transmissíveis, e isto constitui grave problema de saúde pública ${ }^{7}$. 
A rigor, não se conhece o número de infectados pelo HIV nos sistemas prisionais. Entretanto, os dados disponíveis permitem-nos afirmar que são altas as taxas de prevalência do HIV. Muitos sistemas prisionais não dispõem de serviços de saúde e as dificuldades de deslocamento do detento para fora dos sistemas prisionais, tornam ainda mais difícil o acesso dos presos aos serviços sociais".

No final de 1997, pesquisadores da Universidade de São Paulo (USP), após coletarem dados por todo o país, estimaram que cerca de $20 \%$ da população carcerária do Brasil vivia com o HIV. Entre os fatores que contribuíram para este resultado incluem o comportamento sexual de risco e o uso de drogas injetáveis no interior do presídio ${ }^{4}$. Considerando esta estimativa, poderemos ter cerca de 60 mil soropositivos que não constam de nenhum boletim sobre a doença no Brasil. Essa situação pode ser atribuída ao fato de que há uma limitação da divulgação dos dados pela fragilidade do Sistema de Informações de Agravos de Notificação (SINAN) ${ }^{8}$.

As ações e serviços têm por finalidade promover a saúde da população confinada e contribuir para o controle e/ou redução dos agravos mais frequentes que a acometem, e estabelece entre suas prioridades no alcance dessa finalidade a implantação de ações para a prevenção de tuberculose, hanseníase, diabetes, hipertensão, hepatites, DST/AIDS e dos agravos psicossociais decorrentes do confinamento, bem como a distribuição de preservativos e insumos para a redução de danos associados ao uso de drogas9.

Toda ação de prevenção desenvolvida nesses estabelecimentos deverá considerar três contingentes de pessoas a serem atingidas: a pessoa presa, seus familiares (especialmente nos locais onde acontecem visitas íntimas) e os funcionários, através de programas de aconselhamento e de educação continuada para a saúde em parceira com as unidades de saúde locais?.

Para garantir o acesso do detento à saúde, é preciso que a sociedade e os gestores das políticas públicas de saúde, tanto no âmbito federal quanto estadual e municipal, neutralizem seus próprios sentimentos de revolta e de vingança contra a pessoa presa ${ }^{10}$, uma vez que, esses sentimentos são comuns à população e constituem uma das maiores entraves para que o direito à saúde seja universal e equiname, de acordo com os princípios propostos pelo SUS.

Esta pesquisa teve como objetivo conhecer as estratégias desenvolvidas para prevenir a infecção e a disseminação do HIV/AIDS e outras DST nas Delegacias Civis.

\section{Metodologia}

O desenho da pesquisa foi qualitativo, baseada na teoria das representações sociais (TRS).

O público alvo selecionado foi homens $(n=126)$ e mulheres $(n=12)$ aguardando julgamento nas cadeias públicas da região de Naviraí.

A pesquisa realizou-se em Delegacias Civis de cinco municípios do sul do Estado Mato Grosso do Sul que compõem a regional de Naviraí: Mundo Novo, Eldorado, Iguatemi, Itaquiraí e Naviraí. O município de Japorã, que também faz parte dessa regional, até a coleta dos dados não possuía uma unidade de Delegacia Civil, ficando os casos a cargo do município de Mundo Novo.

Os municípios acima estão inseridos na condição de Gestão Plena de Atenção Básica à Saú$\mathrm{de}^{11}$. Oferecem os seguintes serviços à comunidade através das Equipes de Saúde da Família (ESF) e Unidades Básicas de Saúde (UBS): consultas médicas, atendimento odontológico, curativos, aplicação de injeções, inalação, distribuição de medicamentos conforme prescrição médica, preventivo, encaminhamento para centros especializados, programa Tuberculose e Hanseníase (quando há notificação de casos), exame laboratoriais, imunização de rotina, vigilância sanitária, controle de diabetes e da hipertensão através do programa Hiperdia.

Os recursos financeiros são gerenciados pelo Fundo Municipal de Saúde e possui um Conselho Municipal de Saúde que se reúne ordinariamente uma vez por mês. E o sistema público de saúde é formado por unidades próprias que são administradas pela Gerência Municipal de Saúde.

Após o primeiro contato com os (as) internos (as) para maiores esclarecimentos acerca da pesquisa, foram distribuídas duas vias de um Termo de Consentimento Livre e Esclarecido, que depois de lido e assinado, uma via foi arquivada pelo pesquisador e a outra entregue ao entrevistado.

A coleta de dados foi realizada através da técnica de grupo focal, com o auxílio de um gravador de voz, um relator, um observador e um facilitador, seguindo um roteiro não-estruturado para coleta de dados, nos meses de abril e maio/ 2008, nos municípios que compõem a regional de Naviraí. Após a coleta ficou-se à disposição dos detentos para esclarecer dúvidas e orientálos a respeito das DST/AIDS.

Segundo Dias ${ }^{12}$, o objetivo central do grupo focal é identificar percepções, sentimentos, atitudes e ideias dos participantes a respeito de um determinado assunto. O grupo focal se inicia com 
um grupo de seis a 10 pessoas selecionadas com base em suas características, homogêneas ou heterogêneas. A reunião é completamente flexível e não estruturada, dando margem à discussão sobre qualquer assunto.

Após a transcrição das entrevistas, os dados foram analisados utilizando como técnica o Discurso do Sujeito Coletivo (DSC) proposto por Lefèvre e Lefèvre. O DSC é uma técnica de tabulação e organização de dados qualitativos apresentados, uma reunião num só discurso-síntese homogêneo redigido na primeira pessoa do singular de expressões chaves (E-Ch) que tem em a mesma ideia central (ID). A E-Ch é a figura metodológica que revela a essência do depoimento, o que o sujeito falou sobre determinado tema. A IC é a descrição do sentido presente na expressão-chave ${ }^{13}$.

Para chegar ao discurso síntese, foram utilizados os instrumentos de análise de discurso (IAD) I e II. No IAD-I, foram transcritas as E-Ch identificadas em cada entrevista, que expressam os eixos definidos para análise. Após esta transcrição, foram destacadas as IC de cada E-Ch.

No IADII, foram agrupadas e transcritas literalmente as $\mathrm{E}$-Ch de todas as entrevistas que se referem às IC destacadas, sendo possível assim formular um DSC para cada IC. Para a formulação do DSC, foram agrupadas as E-Ch de maneira que formassem um discurso coerente. Para tanto, foram utilizados conectores a fim de dar sentido ao DSC sem que isso alterasse a estrutura da frase elaborada pelo sujeito.

A presente pesquisa foi submetida à análise do Comitê de Ética em Pesquisa Humana, de acordo com a Resolução 196/96 do Ministério da Saú$\mathrm{de}^{14}$, recebendo carta de aprovação.

\section{Resultados e discussão}

\section{Caracterização da amostra}

Foram realizados quatro grupos focais com um total de 30 voluntários para a pesquisa, sendo 22 homens e oito mulheres. A idade destes varia entre 18 e 73 anos, com média de idade de 45,5 anos. Cerca de 80 a $90 \%$ estão detidos por tráfico de drogas e são das mais diversas localidades, até mesmo de outro país. Os restantes 10 a $20 \%$ correspondem a furtos e homicídios. Pertencem a classe de baixa renda e possuem baixa escolaridade. O tempo médio de detenção varia entre três a 15 meses. A maioria não foi condenada e são reincidentes.
As entrevistas foram realizadas nas cidades de Mundo Novo, Itaquiraí e Iguatemi. O município de Naviraí foi excluído da amostra por não ter unidade de detenção para presos provisórios aguardando julgamento. Com a saturação das respostas nos grupos focais realizados, os detentos da delegacia de Eldorado não foram incluídos na pesquisa.

\section{Caracterização do cenário}

As Cadeias Públicas dos municípios acima citados abrigam em média de 20 a 30 detentos. Nestes estabelecimentos os detentos são agrupados em celas. Cada uma destas celas chega a ser ocupada por até cinco presos que são responsáveis por promover a higienização do local.

A construção é antiga e as instalações elétrica e hidráulica são precárias, pois falta manutenção e organização do local. O próprio funcionário de uma das cadeias admite que o local já não está mais em condições de atender as necessidades mínimas que este tipo de estabelecimento exige, e que as condições tanto para os funcionários como para os detentos são as piores possíveis.

As delegacias de polícia são construídas como estabelecimentos pequenos de detenção temporária somente tempo durante necessário à transferência para estabelecimentos penais e normalmente não oferecem infra-estrutura para o trabalho, lazer, educação, visitas ou outras atividades. Em outras palavras, suas plantas físicas são inadequadas e mal equipadas para manter presos por um longo período de tempo.

\section{Eixos de análise}

Os eixos identificados abordados nesta pesquisa são: métodos de prevenção conhecidos e utilizados e assistência à saúde sob a ótica dos detentos.

Surgiram também outros eixos, principalmente com relação a casos de DST/AIDS vivenciados pelos detentos dentro e fora do sistema de detenção, conhecimentos sobre DST/AIDS, discriminação e preconceito, atuais condições das Cadeias Públicas, dificuldade em conseguir transferência para um presídio e dos processos demasiadamente demorados. Estes foram observados em todos os discursos, porém não são o objetivo desta pesquisa. Contudo, merecem atenção das autoridades locais, estaduais e federais e de mais estudos na área afim. 


\section{Métodos de prevenção}

\section{DSC}

Homens: As DST se previne usando preservativo, né? O mais seguro é, ou a mulher, né? A gente nunca viu elas usar. Mas se elas quisé a gente toparia. Mas, com a minha mulher eu nunca usei não, não me sentia a vontade não. Só se for o primeiro encontro, aí dentro tem, mas depois que já fez é como chupar bala com papel. Elas também não tão nem aí, só querem prazer. Teve um rapaz que tava namorando uma mulher ai que trazia sempre, mas ai ela ficou com vergonha, vai que alguém mexe na bolsa e vê as camisinha aí, ela falou desse jeito. Se minha mulher pegasse aquelas camisinhas ali ela ia pensar que eu tava com má intenção, desconfiando de mim. Mas não tem distribuição de camisinha aqui não. Nem pra quem tem visita intima. E eu duvido quem usa uma camisinha dentro da cadeia, é raro, hein.

Mulheres: Uso camisinha. É o método mais seguro. Claro porque eu to presa, mas ele não, ele ta bem solto. Ah, o mais seguro seria não ter (relação sexual). Mas tem outro método mais seguro ainda (mostra o dedo). Mas, dá última vez que ele veio eu fiquei meio assim, mas eu não usei não, confio nele. Quando eu vou no postinho aí eu pego preservativo, então ela dá um tanto de preservativo que é pra mim dar também pra quem tem visita intima, então no caso pra R. e da última vez que eu peguei, que faz uns quatro ou cinco meses eu dei umas pra ela e a M. usa no dedinho também.

Uma análise global do discurso acima permite concluir que os detentos conhecem os principais métodos de prevenção, porém esses são utilizados esporadicamente tanto pelo próprio desinteresse com pela falta de orientação da equipe de saúde local sobre a temática para esta população.

O uso consistente de preservativo foi considerado pelos detentos a medida mais eficiente na interrupção da transmissão das DST/AIDS. Segundo Ministério da Saúde ${ }^{15}$, esta medida é considerada segura pela grande maioria da população brasileira (94\%) como forma de prevenção dessas infecções.

O preservativo masculino é popularmente conhecido. Já o feminino ainda é pouco difundido, mas eles sabem que existem, porém muitos nunca viram ou nunca usaram. Segundo o Ministério da Saúde ${ }^{2}$, o preservativo feminino só é distribuído em alguns serviços de saúde e por Organizações Não-Governamentais. O custo elevado desse insumo impossibilita um investimento nas mesmas proporções do masculino, entretan- to, tal investimento torna-se mais importante no atual panorama da AIDS no Brasil, em que aumenta muito o número de casos de AIDS entre mulheres.

Muitas vezes, associa-se o aumento de mulheres infectadas pelo HIV/AIDS com a dificuldade de negociar o uso do preservativo com o seu parceiro sexual. Este fato não é observado no discurso, pois apesar de não conhecerem o preservativo feminino, se o uso deste fosse proposto pela parceira, os detentos aceitariam usá-lo. Logo, pode-se perceber que o preservativo não é utilizado porque mulheres e homens não negociam seu uso.

Jimenez et al. ${ }^{16}$, sugerem que o principal fator preditivo para o não uso do preservativo (masculino ou feminino) é a presença de parceiro fixo, realidade observada também nas cadeias públicas. Os casais que mantém um relacionamento há mais tempo com parceiros (as) fixos (as), cuja união estável foi comprovada para ter direito de receber visitas íntimas, não fazem questão de se prevenir. Ainda segundo os autores acima citados, não se sentir em risco, provavelmente, está associado ao pouco conhecimento da população sobre a possibilidade de se contaminarem. Tem sido considerado pouco provável que as mulheres pensem na possibilidade de contaminar-se com DST/HIV, pois não se consideram promíscuas, confiam e conhecem seus parceiros e têm relações sexuais envolvidas em sentimentos afetivos.

Essa resistência ao uso do preservativo com parceiro (a) fixo (a) é comum tanto nas cadeias como fora dela. Em algumas situações onde a sorologia para HIV é conhecida e constatada negativa para ambos, pode-se deixar de usar o preservativo $^{2}$. Todavia, as DST não são diagnosticadas nestes exames, logo, ninguém, mesmo que pratique a monogamia, está livre de adquiri-la, considerando ainda o ambiente propício que é a cadeia devido à aglomeração de pessoas e às más condições habitacionais.

Antes dessa união se tornar estável, há relato do uso do preservativo somente no primeiro encontro, provando que, após este acontecer, tanto o detento como a pessoa livre não se importam em praticar sexo sem proteção, pois alegam que "depois que já fez é como chupar bala com papel”. Aí retornamos com a questão da resistência do uso com parceiras (os) fixas (os).

Quando, raramente, o preservativo é utilizado, é por iniciativa da companheira ou da detenta ou ainda, quando o preservativo é trazido junto com os pertences do detento assim que a prisão é decretada. Algumas poucas mulheres que tive- 
ram a iniciativa de levar o preservativo para as visitas íntimas acabaram desistindo por vergonha na hora da revista realizada pelos funcionários das cadeias. Os detentos ainda argumentam que se eles propuserem o uso da camisinha para suas parceiras, estas interpretarão como um ato de desconfiança sobre sua fidelidade.

Segundo Barbosa ${ }^{17}$, o número de homens detidos que recebem cota de preservativos vem aumentando, bem como o número daqueles que solicitam o teste anti-HIV. Aqui, depara-se com duas realizadas diferentes. Nas cadeias onde a pesquisa foi aplicada, não há distribuição de preservativos. Porém, ao serem questionados sobre a solicitação dos preservativos eles alegam que nunca tentaram, porque sabem que dificilmente serão atendidos, uma vez que a prioridade é dada para a população em liberdade. Já para as mulheres o preservativo é fornecido na mesma oportunidade, eventualmente, quando estas solicitam o atendimento de saúde. Contudo, ao serem questionados sobre o teste anti-HIV, eles demonstraram grande interesse, isso mostra que em algum momento de suas vidas passaram por uma situação vulnerável com riscos de contrair o vírus HIV.

Traçando uma analogia entre os discursos dos homens e das mulheres, observa-se que não há grandes diferenças em relação aos métodos de prevenção, mesmo porque as situações na maioria das cadeias não diferem em si. O único aspecto distinto encontrado é quanto a ocorrência das visitas íntimas, que para os homens estas ocorrem com mais frequência, cerca de $90 \%$ segundo Barbosa ${ }^{17}$, se comparado ao número de mulheres que mantém relações com o parceiro na cadeia. Esta diferença está relacionada com a distância em que o parceiro se encontra, muitos deles também estão detidos em outras localidades, o que impossibilita a visita para ambos.

Comprovando a situação das mulheres presas, Scolese ${ }^{18}$, destaca que nos estabelecimentos penais femininos do país $62 \%$ das mulheres não recebem visitas sociais. $\mathrm{O}$ isolamento é ainda mais nítido em visitas íntimas: apenas 9\% das presas recebem esse tipo de visita.

\section{Assistência à saúde}

\section{DSC}

"A assistência dentro da cadeia é precária. Porque é o seguinte, pra fazer um exame aqui é difícil, pra levar o cara no pronto socorro demo- ra uns três, quatro dias. E quando consegue você chega lá o médico nem olha pra sua cara, primeira coisa, pra falar pra ele nem vai um segundo, meia hora que for. Não A pessoa que ficar doente se não comer, não tentar reagir de alguma forma mesmo como dá, morre. Quando tem alguma gripe pra vir um médico aqui é a maior confusão, imagina com um problema deste, maior sofrimento. Por exemplo, se tiver uma emergência, uma cólica de rim é difícil eles vim no mesmo dia e na hora, tem que esperar o dia de visita pra o parente vir e ver o que ta acontecendo pra marcar a consulta. Aqui ninguém passa orientação de nada, só quer saber de jogar aqui e "já era". Somos abandonados pela Lei. Aqui a gente fica ao léu, se não tiver fé em Deus...

Homens e mulheres presos em cadeias públicas têm seus direitos negligenciados pelo atual sistema carcerário".

O sistema carcerário brasileiro tem sido sistematicamente criticado por várias instâncias sociais nacionais e internacionais de defesa dos direitos humanos, por estar em frequente superlotação; condições inadequadas de vida, quando não insalubres; ociosidade. As instituições produzem regras próprias, muitas vezes discriminatórias e favorecedoras de riscos à saúde e de constrangimentos 9 .

A pena reside apenas na privação da liberdade, e não na privação dos direitos humanos fundamentais ${ }^{19}$. Como todas as pessoas, portanto, a população privada de liberdade tem o direito de acesso à saúde com os atendimentos equivalentes aos fornecidos à população em geral de acordo com o que a cidade pode oferecer, incluindo medidas preventivas. No entanto, observou-se que a assistência prestada à população detida não equivale com a prestada à população em geral, mesmo que esta ainda seja deficitária.

Além da dificuldade para realizar uma consulta ou um exame, quando este é fornecido, chegando ao serviço de saúde o detento encontra outro obstáculo, a discriminação. A condição de preso já desperta nas pessoas certo receio e desconfiança. Contrapondo esta realidade, a ONU ${ }^{19}$ estabelece que a população privada de liberdade tenha o direito, sem discriminação, a atenção à saúde equivalente ao que está disponível para a comunidade em geral.

O preconceito e a desvalorização do preso e de sua queixa são acompanhados de uma avaliação informal da demanda de assistência por parte dos agentes de segurança penitenciária ${ }^{18}$, os funcionários que avaliam a necessidade ou não de atendimento, postergando até que não seja 
mais possível a assistência nesta modalidade de detenção.

Nestes casos em que é necessário um atendimento mais especializado em um presídio, por exemplo, encontra-se outro entrave, a dificuldade de transferência. No discurso há referência de dois casos como este. Um deles acabou tragicamente, o outro ainda estava em fase de negociação, do qual não se sabe como se deu a resolução.

Outro fato interessante presente no discurso, é quanto a dinâmica de algumas delegacias com relação ao atendimento à saúde. A marcação de consultas por meio dos parentes e familiares foi a forma encontrada para que os detentos pudessem ser atendidos, mesmo assim o atendimento é demorado, pois até que o familiar tome conhecimento da situação leva um certo tempo e ainda há o período de esperada para a consulta, rotina essa que a população em geral também enfrenta. Para os detentos que não residiam na cidade onde está preso, a problemática é ainda maior. Sobre esta estratégia não há menção encontrada nos estudos realizados até o momento.

Falar em saúde do preso, direito humano, direito constitucional de todos os brasileiros soa como privilégio. Porém, a pessoa livre quando não atendida, tem o direito e acesso aos meios legais que lhe são garantidos constitucionalmente. Já a pessoa presa não tem a chave da cela para abri-la no momento da dor, não tem direito de sair livremente para buscar o atendimento. Está sob a custódia do Estado, é conduzida ${ }^{17}$.

Diante das condutas tomadas por alguns profissionais de saúde que os detentos consideram inadequadas, e que realmente são, estes preferem esperar a "auto-cura" do que se submeter ao seu atendimento.

As Cadeias Públicas, como já mencionado, não são contempladas pelo Plano Nacional de Saúde no Sistema Penitenciário, gerando uma dúvida em quem seriam os responsáveis pela prestação de atendimento à população recolhida neste estabelecimento.

Alguns municípios e estados brasileiros já realizaram em suas delegacias e/ou unidades prisionais, programas de aconselhamento e de educação continuada para a saúde, e muitas vezes, tais programas são desenvolvidos em parceria com as unidades de saúde locais ${ }^{9}$. Uma estratégia que serve de modelo para outros municípios que não desejam que seus cidadãos estejam à mercê somente da própria sorte em adoecer ou não.

Mesmo que os detentos muitas vezes vivam em péssimas condições, ainda não são todos que se surpreendem com as condições de saúde como as destacadas até então. Esta é interpretada como se fosse parte de sua pena, por ter infringido a lei. Teixeira ${ }^{5}$ completa, que para o preso não resta muito mais do que o confinamento insalubre.

\section{Considerações finais}

As DST e a AIDS, sem dúvida, representam uma séria ameaça à saúde da população privada de liberdade em nosso país, que o sistema público de saúde nem sempre consegue atingir.

Todavia, embora reconheçam que a prevenção é importante, a utilização de métodos preventivos é esporádica, por três motivos principais: a dificuldade em adquirir o preservativo, a falta de orientação e a relação estável com parceria(o) fixa(o). Para aqueles que não recebem visita íntima a abstinência é a estratégia imposta, pois negam a existência de relações homossexuais dentro da cadeia.

Em algumas unidades de saúde locais o atendimento aos detentos faz parte de sua programação mensal. Mas ainda nem todos os municípios estão sensibilizados da necessidade de realizar a assistência a esta população, bem como preparar e capacitar os profissionais.

Hoje discute-se muito sobre a temática da prevenção, sendo esta o grande objetivo das novas estratégias em saúde pública, porém quando procurou-se, através desta pesquisa, abordar esta temática com a população, há uma certa limitação de dados, mostrando ser necessário aprofundar a discussão em torno de ações que visem sensibilizar a importância da assistência preventiva nas cadeias públicas.

Diante da considerável relevância do tema e da atual situação do sistema carcerário, uma cópia deste relatório será entregue às unidades de Delegacias Civis onde a pesquisa foi aplicada e à respectiva Secretaria de Saúde do município, a fim de que, através dos resultados obtidos, novas ações e estratégias possam ser elaboradas, garantindo assim o direito à saúde, que sob nenhuma circunstância deve ser negado ao ser humano. 


\section{Colaboradores}

Reis CB e Bernardes EB participaram igualmente de todas as etapas da elaboração do artigo.

\section{Referências}

1. Brasil. Ministério da Saúde. Secretaria de Vigilância em Saúde. Guia de vigilância epidemiológica. $6^{a}$ ed. Brasília: Ministério da Saúde; 2005.

2. Brasil. Ministério da Saúde. Secretaria executiva. Coordenação Nacional de DST e AIDS. Políticas e diretrizes de prevenção das DST/AIDS entre as mulheres. Brasília: Ministério da Saúde; 2003.

3. Brasil. Ministério da Saúde. Secretaria de Vigilância em Saúde. Programa Nacional de DST e AIDS. Pesquisa entre conscritos do Exército Brasileiro 19962002: retratos do comportamento de risco do jovem brasileiro pelo HIV. Brasília: Ministério da Saúde; 2006. (Série Estudos Pesquisas e Avaliação no 2)

4. Cardoso Jr R. Prevalência do HIV nos presídios. Boletim Direitos Humanos HIV/AIDS. Brasília: Ministério da Saúde 2001, ano V(1). [acessado 2007 mar 15]. Disponível em: http://www.aids.gov.br/final/ dh/bol_5_1/prevelencia.htm.

5. Teixeira PRA. A AIDS nos presídios. Boletim Direitos Humanos HIV/AIDS. Brasília: Ministério da Saúde 2001, ano V(1). [acessado 2007 abr 15]. Disponível em: http://www.aids.gov.br/final/dh/bol_5_1/index. htm

6. Brasil. Ministério da Saúde. Secretaria de Atenção à Saúde. Departamento de Ações Programáticas Estratégicas. Plano nacional de saúde no sistema penitenciário. Brasília: Ministério da Saúde, 2004.

7. Massad E. HIV/AIDS no sistema prisional brasileiro. 2001. [acessado 2007 abr 10]. Disponível em: http:/ /salves.com.br/virtual/aidssistcarc.htm

8. Gimenez R, Pecoraro M, Bonanno L. População carcerária: a caixa preta da AIDS no Brasil. Agência de notícias da AIDS; 2003.

9. Brasil. Ministério da Saúde. Secretaria de Vigilância Epidemiológica em Saúde. Programa Nacional de DST/AIDS. Implicações éticas de diagnóstico e da triagem sorológica do HIV. Brasília: Ministério da Saúde; 2004.

10. Barros ARR. O acesso do detento à saúde. Boletim Direitos Humanos HIV/AIDS. Brasília: Ministério da Saúde 2001, ano V(1). [acessado 2007 abr 12]. Disponível em: http://www.aids.gov.br/final/dh/ bol_5_1/acesso.htm.

11. Brasil. Ministério da Saúde. NOAS-SUS. Portaria n. 373, de 27 de fevereiro de 2002. Brasília: Ministério da Saúde; 2002.

12. Dias CA. Grupo Focal: técnica de coleta de dados em pesquisas qualitativas. Revista Informação \& Sociedade: Estudos 2000; 10(2):141-158.
13. Lefèvre F, Lefèvre AMC. O Discurso do Sujeito Coletivo: um novo enfoque em pesquisa qualitativa. Caxias do Sul: Educs; 2003. (Desdobramentos)

14. Brasil. Ministério da Saúde. Fundação Nacional de Saúde. Centro Nacional de Epidemiologia. Normas de pesquisa envolvendo seres humanos - Resolução 196/96. Informe Epidemiológico do SUS. Brasília: Ministério da Saúde 1996; 5(2):13-30.

15. Brasil. Ministério da Saúde. Resposta positiva: experiências do programa brasileiro de AIDS. Brasília: Ministério da Saúde; 2005b.

16. Jimenez AL, Gotlieb SLD, Hardy E, Zaneveld LJD. Prevenção de doenças sexualmente transmissíveis em mulheres: associação com variáveis sócio-econômicas e demográficas. Cad Saude Publica 2001; 17(1):55-62.

17. Barbosa AS. AIDS na frente das grades: o descuido à cidadania. Boletim Direitos Humanos HIV/AIDS. Brasília: Ministério da Saúde 2001, 5(1). [acessado 2007 abr 12]. Disponível em: http://www.aids.gov.br/ final/dh/bol_5_1/acesso.htm.

18. Scolese E. Apenas $9 \%$ das presas têm visita íntima. Folha de São Paulo, São Paulo, 26 maio 2008. Folha Cotidiano. [acessado 2008 ago 15]. Disponível em: http://www.observatoriodeseguranca.org/node/480.

19. Organização das Nações Unidas (ONU). Escritório das Nações Unidade Contra Drogas e Crime. HIV/ AIDS em ambientes prisionais: prevenção, atenção, tratamento e apoio. Nova York: Nações Unidas; 2007.

Artigo apresentado em 05/03/2009

Aprovado em 03/09/2009

Versão final apresentada em 01/10/2009 